\title{
Feasibility and Outcome of Allogeneic Hematopoietic Stem Cell Transplantation in 30 Patients with Poor Risk Acute Myeloid Leukemia Older than 60 Years
}

\author{
Candoni Anna*, Simeone Erica, Cerno Michela, Sperotto Alessandra and Fanin Renato
}

\author{
Division of Haematology and Bone Marrow Transplantation, Department of Medical and Morphological Researches \\ (DMMR), University of Udine, Italy
}

\begin{abstract}
We report on the feasibility and outcome of allogeneic SCT (allo-SCT) in 30 poor risk AML patients older than 60 years. Median age at transplant was 63 years (range 60-70 years) and 18/30 (60\%) cases were in complete remission. Donors were MUD in $40 \%$ and sibling in $60 \%$ of cases. Twenty-six of 30 patients $(87 \%)$ received a reduced intensity conditioning regimen (RIC). The hematopoietic cell transplantation specific comorbidity index (HCT-CI) was two or less in $12 / 30$ cases and three or more in 18/30 cases. All patients engrafted. One year Nonrelapse mortality (NRM) rate was $20 \%(6 / 30$ cases $)$. After a median follow-up of 16 months $17 / 30$ patients $(57 \%)$ were alive and in complete remission while 13/30 (43\%) have died (leukemia refractory or relapse 7/13 and NRM 6/13). Median Overall Survival for the whole patient population was 28 months. The Overall Survival did not differ between unrelated and related donors. The patients transplanted in complete remission had a significantly lower survival rate and relapse rate compared to those transplanted with refractory or relapsed AML $(\mathrm{P}=0.0004$ and $\mathrm{P}=0.008$ respectively). The patients with a low HCT-CI ( 2 or less $)$ had a significantly lower NRM $(\mathrm{P}=0.03)$ and survival rate $(\mathrm{P}=0.02)$ compared to those with HCT-CI 3 or more.

Taking into account that this is a retrospective analysis with a small number of cases, these results confirm the feasibility of allo-SCT for high risk AML patients older than 60 years. Outcome was significantly influenced by status of disease at transplant and by HCT-CI. We also confirm that for older patients lacking a family donor MUD can provide a suitable alternative option.
\end{abstract}

Keywords: Acute leukemia, hematopoietic stem cell transplantation, comorbidity index.

\section{INTRODUCTION}

Older age is one of the most important adverse prognostic factors in Acute Myeloid Leukemia (AML) [1,2]. Allogeneic stem cell transplantation (allo-SCT) is one of the most recommended approaches in poor prognosis AML but there are limited data about this procedure in elderly AML patients [1-4]. The results of allo-SCT seem to be improved in terms of lower transplant related toxicity with the development of so-called reduced intensity conditioning (RIC) regimens. The introduction of RIC transplant has increased the percentage of AML candidate to allo-SCT procedure [5,6]. Nevertheless, most of the largest studies reported in the literature with RIC or conventional regimes in older than 60 years include cases with heterogeneous clonal hematopoietic disorders (a mix of acute and chronic myeloid leukemia and lymphomas).

We report on our experience about the feasibility and the outcome of the allo-SCT from a series of 30 AML patients older than 60 years.

\section{PATIENTS AND METHODS}

Between 1 January 2004 and 31 December 2009, 30 patients aged over 60 years with AML underwent allo-SCT

\footnotetext{
*Address correspondence to this author at the Division of Hematology and Bone Marrow Transplantation Unit, University of Udine, Italy; Tel: 0432559662; Fax: 0432 559661; E-mail: candoni.anna@aoud.sanita.fvg.it
}

at our Centre. Baseline patient characteristics are reported in Table 1. All 30 cases were at high risk at diagnosis because of therapy related or secondary AML, unfavourable karyotype $(-5,-7,11 \mathrm{q} 23$, complex karyotype) or a blast count $>30 \times 10^{9} / 1$. Donor-search, either within the family or in volunteer donor Registries worldwide, was performed during induction chemotherapy. All patients provided written informed consent for transplantation protocols that were approved by the institution Ethic Committee. The hematopoietic cell transplantation specific comorbidity index (HCT-CI) was two or less in $12 / 30$ cases $(40 \%)$ and three or more in $18 / 30$ cases $(60 \%)$.

Allo-SCT conditioning regimens were employed according the national ongoing trials. Conditioning regimen consisted of Thyotepa + Cyclophosphamide \pm ATG in 14/30 (47\%) of cases, Fludarabine-based RIC in 12/30 (40\%) of cases, Busulfan + Cyclophos-phamide \pm ATG in 4/30 (13\%) of cases. Twenty-six of 30 patients $(87 \%)$ received a reduced intensity conditioning regimen (RIC) and $4(13 \%)$ a myeloablative one (Table $\mathbf{1}$ ). Graft Versus Host Disease (GvHD) prophylaxis consisted of intravenous cyclosporine $(3-5 \mathrm{mg} / \mathrm{kg})$ and methotrexate $(10$ $\mathrm{mg} / \mathrm{m}^{2}$ on days $1,3,6$ and 11$)$. One patient received cyclosporine alone and one received cyclosporine in combination with mycophenolate mofetil (MMF). Cyclosporine was given orally as soon as the patients were able to swallow. Matched unrelated donor (MUD) recipients received also anti-T lymphocyte globulin 40 to $60 \mathrm{mg} / \mathrm{kg}$ body weight (ATG-S; Fresenius, Grafelfing, Germany). Patients were housed in rooms 
with HEPA-filtered air. All patients received prophylactic antimicrobial therapy with levofloxacine and fluconazole from admission until engraftment. Toxicities were graded according to the World Health Organization (WHO) criteria [7]. Acute and chronic GvHD were graded and staged by standard criteria [8]. Neutrophil and platelet recovery were defined as the first of two consecutive days with Absolute Neutrophil Count (ANC) $>1 \times 10^{9} / 1$ and platelets (PTL) $>50 \times 10^{9} / 1$ without transfusions, respectively. Chimerism was tested after 1 month and at 3 month intervals with PCR analysis of microsatellite markers [9]. AML response and relapse were determined by standard hematologic criteria [10].

Table 1. Patients and Transplant Characteristics

\begin{tabular}{|c|c|c|}
\hline & $\mathbf{N}^{\circ}$ & $\%$ \\
\hline SEX Male/Female & $14 / 16$ & \\
\hline $\begin{array}{l}\text { AGE at BMT, years } \\
\qquad \quad \text { Median (Range) } \\
>\mathbf{6 5} \mathrm{yrs}\end{array}$ & $\begin{array}{c}63(60-70) \\
13 / 30\end{array}$ & 43 \\
\hline HIGH RISK at Diagnosis & $30 / 30$ & 100 \\
\hline $\begin{array}{cl}\text { STATUS at BMT } \\
\text { - } & \mathrm{CR} \\
\text { - } & \mathrm{REL} / \mathrm{RES}\end{array}$ & $\begin{array}{l}18 / 30 \\
12 / 30\end{array}$ & $\begin{array}{l}60 \\
40\end{array}$ \\
\hline $\begin{array}{c}\text { HCT-CI } \\
\cdot \quad \leq 2 \\
\cdot \quad \geq 3\end{array}$ & $\begin{array}{l}12 / 30 \\
18 / 30\end{array}$ & $\begin{array}{l}40 \\
60\end{array}$ \\
\hline $\begin{array}{cl}\text { DONOR } & \\
\bullet & \text { SIBLING } \\
\bullet & \text { UNRELATED }\end{array}$ & $\begin{array}{l}18 / 30 \\
12 / 30\end{array}$ & $\begin{array}{l}60 \\
30\end{array}$ \\
\hline $\begin{array}{l}\text { PREPARATIVE REGIMENS } \\
\text { - Tyotepa-cyclophosphamide } \pm \text { ATG } \\
\text { - } \quad \text { Busulfan-cyclophosphamide } \pm \text { ATG } \\
\text { - } \quad \text { Fludarabine-based RIC }\end{array}$ & $\begin{array}{c}14 / 30 \\
4 / 30 \\
12 / 30\end{array}$ & $\begin{array}{l}46 \\
14 \\
40\end{array}$ \\
\hline RIC & $26 / 30$ & 87 \\
\hline 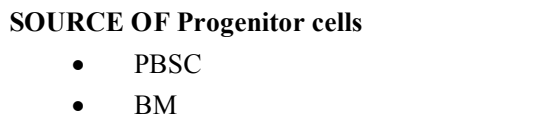 & $\begin{array}{l}19 / 30 \\
11 / 30\end{array}$ & $\begin{array}{l}63 \\
37\end{array}$ \\
\hline $\begin{array}{l}\text { Median CD34+ cells within the graft } \\
\times 10^{6} \text { (range) }\end{array}$ & $\begin{array}{c}5 \\
(0.8-18.5)\end{array}$ & \\
\hline
\end{tabular}

bone marrow; PBSC peripheral blood stem cells; RIC, reduced intensity conditioning.

Overall survival (OS) was computed from transplant date until death or last follow-up. Patient's last follow-up was march 31, 2010. Survival curves were constructed using the Kaplan-Meier method. Patient's characteristics were compared by the Fisher's exact test for categoric variables. $P$-value less than 0.05 was considered as statistical significant. Data were analysed using NCSS60 software (NCSS Company, Kaysville, UT, USA).

\section{RESULTS}

\section{Transplantation Details and Engraftment}

The median time from diagnosis to transplant was 7 months. The median age at transplant was 63 years (range
60-70) and 13 patients (43\%) were older than 65 years. At the time of transplantation, 18 cases $(60 \%)$ were in complete remission (CR), while $12(40 \%)$ had an active disease (relapsed or refractory AML). The comorbidities included: hypertension ( 9 patients), diabetes mellitus (3 patients), stable heart diseases ( 5 patients), hepatic or renal diseases ( 3 patients). Besides 8 patients had a prior history of solid tumours that required chemotherapy (of which 2 had multiple tumours). Eighteen patients $(60 \%)$ received an allograft from a sibling, 12 (40\%) from an unrelated donor. The median age of sibling donors was 63 years (range 39-73) compared to 39 years (range 27-48) of unrelated donors $(\mathrm{P}<$ $0.05)$. Stem cell source was bone marrow (BM) in $11(37 \%)$ and unmanipulated peripheral blood (PB) in $19(63 \%)$ patients. Median number of CD34+ cells was $5 \times 10^{6} / \mathrm{kg}$ body weight (range $0,8-18.5$ ), significantly higher in $\mathrm{PB}$ than in $\mathrm{BM}$ recipients $\left(6.5\right.$ vs $\left.1.6 \times 10^{6} / \mathrm{kg}, \mathrm{P}<0.05\right)$.

All patients became neutropenic $\left(\mathrm{ANC}<0.5 \times 10^{9} / 1\right)$ and thrombocytopenic (PLT $\left.<20 \times 10^{9} / 1\right)$, requiring a median of 4 platelet transfusions (range, 1-30) and a median of 7 erythrocyte transfusions (range, 1-30). All patients engrafted. The median time to neutrophil and platelet recovery was 18 (range 12-31) and 19 days (range 10-60), respectively, without differences according to stem cell source (BM or PB) (Table 2). Chimerism analysis was available in $25 / 30$ cases: at the first testing after engraftment (day 35), 17/25 (68\%) patients had complete donor chimerism and $8 / 25$ (32\%) had mixed chimerism (60\% to $98 \%$ donor). Data were not available for 5 patients: two died early, two had persistent leukemia and 1 was not tested for other reasons.

\section{GvHD, Toxicity and Outcome}

As presented in Table 2, all 30 patients were assessable for acute GvHD. Acute GvHD was observed in 17/30 patients (56\%) with 13 having grades I-II and 4 having grades III-IV. Data on chronic GvHD was available for $22 / 30$ patients (73\%); of those $2 / 22$ (9\%) experienced extensive chronic GvHD requiring prolonged immunosuppressive therapy and 9/22 (41\%) had limited chronic GvHD. Data summarizing haematological recovery, transfusion support and more relevant toxicity are reported in Table 2. Grade 3-4 mucositis occurred in 5/30 (17\%) patients. Infections occurred in 16 patients $(53 \%)$, including 14 cases of bacteraemia and 9 cases of pneumonia (4 bacteria, 3 aspergillus, 1 Pneumocystis and 1 Cytomegalovirus). Infectious death occurred in 3 patients who developed pneumonia, septic shock and multi-organ failure. No cases of Veno Occlusive Disease were reported. One year Nonrelapse mortality (NRM) rate was 20\% (6/30 cases). Causes of NRM were: pneumonia with septic shock $(n=1)$, acute GvHD $(n=3)$, sudden cardiac death (1), and intracranial haemorrhage $(n=1)$. The median length of hospital stay, for allo-SCT, was 40 days (range 28-90).

At the time of analysis, after a median follow-up of 17 months (range 1-64), 17/30 patients (57\%) were alive and in complete remission while 13/30 (43\%) have died (leukemia refractory or relapse $7 / 13$ and NRM 6/13). The median follow-up for transplant survivors was 27 months (range 264). Median Overall Survival (OS) for the whole patient population was 28 months (Fig. 1). One year probability of Overall Survival (OS) was $57 \%$ (95\% CI: $24 \%$ to $81 \%$ ). The 
OS and toxicity did not differ between sibling and MUD recipients. The patients transplanted in complete remission have a significantly better survival rate $(\mathrm{P}=0.0004)$ and lower relapse rate $(\mathrm{P}=0,008)$ compared to those transplanted with active AML (Table 3). The patients with a low HCT-CI ( 2 or less) have a significantly better survival rate $(\mathrm{P}=0.02)$ and lower Non Relapse Mortality (NRM) $(\mathrm{P}=0.03)$ compared to those with HCT-CI 3 or more (Table 3 ).

Table 2. Hematopoietic Recovery and Non-Haematologic Toxicity

\begin{tabular}{|c|c|c|}
\hline & $\mathbf{N}^{\circ}$ & $\%$ \\
\hline $\begin{array}{ll}\text { ENGRAFTMENT } \\
\text { - } & \text { ANC }>1 \times 10^{9} / \mathrm{L}, \text { median days (range) } \\
\text { - } & \text { PLT }>50 \times 10^{9} / \mathrm{L}, \text { median days (range) } \\
\text { - } & \text { Packed red cells units, median (range) } \\
\text { - } & \text { Platelet units, median (range) } \\
\text { - } & \text { Hospitalisation, median days (range) }\end{array}$ & $\begin{array}{c}30 / 30 \\
18(12-31) \\
19(10-60) \\
7(1-30) \\
4(1-30) \\
40(28-90)\end{array}$ & 100 \\
\hline $\begin{array}{l}\text { GVHD } \\
\text { ACUTE GVHD (N\%/evaluable pts) } \\
\text { Grade 1-2 } \\
\text { Grade 3-4 } \\
\text { CHRONIC GVHD (N\%/evaluable pts) } \\
\text { Limited } \\
\text { Extensive }\end{array}$ & $\begin{array}{c}17 / 30 \\
13 / 30 \\
4 / 30 \\
11 / 22 \\
9 / 22 \\
2 / 22\end{array}$ & $\begin{array}{c}57 \\
43 \\
14 \\
50 \\
41 \\
9\end{array}$ \\
\hline $\begin{array}{ll}\text { COMPLICATIONS } \\
\text { - } & \text { Mucositis grade III/IV } \\
\text { - } & \text { Pneumonia } \\
\text { - } & \text { Bacteremia } \\
\text { - } & \text { CMV infectious } \\
\text { - } & \text { Haemorrage grade III/IV } \\
\text { - } & \text { Cardiotoxicity } \\
\text { - } & \text { Liver toxicity grade III/IV } \\
\text { - } & \text { VOD }\end{array}$ & $\begin{array}{c}5 / 30 \\
9 / 30 \\
14 / 30 \\
10 / 30 \\
2 / 30 \\
5 / 30 \\
2 / 30 \\
0 / 30\end{array}$ & $\begin{array}{c}17 \\
30 \\
47 \\
33 \\
6 \\
15 \\
6 \\
0\end{array}$ \\
\hline $\begin{array}{l}1 \text { year Overall Survival } \\
2 \text { year Disease Free Survival }\end{array}$ & $\begin{array}{r}57 \\
(95 \% \mathrm{CI}: \\
35 \\
(95 \% \mathrm{CI}:\end{array}$ & $\begin{array}{l}81 \%) \\
82 \%)\end{array}$ \\
\hline
\end{tabular}

\section{DISCUSSION}

The incidence of acute myeloid leukemia (AML) increases with age and over half of the AML patients at diagnosis are older than 60 years [1,2]. Despite improvements in chemotherapy and supportive care, the prognosis of AML patients older than 60 years remains poor and cure is rarely achieved using conventional chemotherapy (with 2 year disease free survival rates lower than $20 \%$ ) $[1,2$, 11]. Allogeneic hematopoietic stem cell transplantation (allo-SCT) is a curative option, but the issues of its safety and efficacy in elderly patients are still under debate [11, 12]. In fact the risk of Nonrelapse mortality (NRM) increases with age, particularly after 55-60 years. The development of reduced intensity conditioning (RIC) regimens has upraised the age limit for allo-SCT over 60 years, mainly by reducing the impact of NRM [11-13]. The studies reported in the literature with RIC or conventional regimes in patients aged $\geq 60$ years are rare and include cases with heterogeneous clonal hematopoietic disorders (acute and chronic myeloid leukemia, lymphomas). As reported in Table 4 a limited data have been available regarding allo-SCT in AML patients older than 60 years $[5,15-18]$.

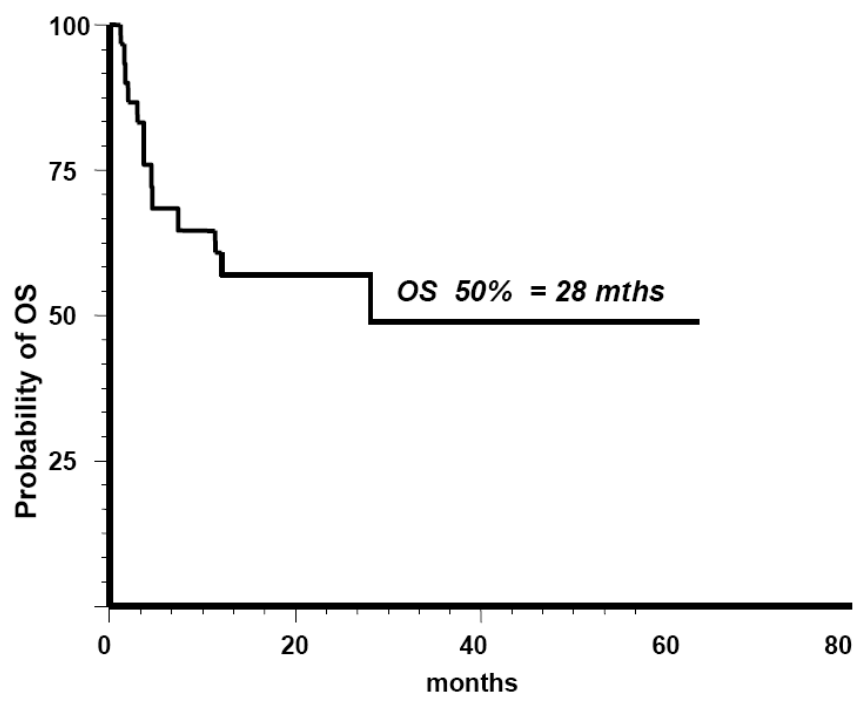

Fig. (1). Median Overall Survival (OS) of The whole Population after Allo-SCT was 28 months.

In the study by Bertz et al. 19 AML patients above the age of 60 underwent RIC-SCT from matched related and unrelated donors. The median age of patients was 64 years (range 60-70) and the majority of them had active disease. Conditioning consisted of fludarabine, melphalan, and carmustine. All patients engrafted and 13 out $19(68 \%)$ achieved complete remission. With a median follow-up period of 825 days (range 595-1028), the OS was 68\% without differences between MUD and sibling SCT. The 1year NRM rate was $22 \%$ [5]. Shapira et al. reported 17 cases of AML, median age 62,5 years (range 60-67), conditioned with fludarabine plus busulfan, resulting in a NRM and OS of $33 \%$ and $29 \%$, respectively, with a median follow-up of 11 months (range 8-53) [15]. Gupta et al. reported the outcome of 24 patients aged $\geq 60$ with poor-prognosis myelodysplastic syndromes or AML, undergoing RIC-SCT; NRM at 100 days and after 2 years was $8 \%$ and $25 \%$, respectively. The probability of 1 and 2 year OS was $60 \%$ an $52 \%$, respectively [16]. Also, the experiences by De Lima and Falda et al. suggest that allo-SCT is feasible in selected older poor prognosis AML patients $[17,18]$.

Our present experience confirms that allo-SCT may be a suitable option for elderly AML patients. In addition, it should be underlined that in our series $43 \%$ of patients were aged over 65 years. Despite that, NRM rate was low (20\%) and the survival and toxicity were similar in recipient of sibling and unrelated donor SCT. Our results of a similar outcome of MUD transplantation compared with sibling transplantation may be due to the improvement (in recent years) of GvHD prevention and treatment, infection treatment and prophylaxis and could also be related to the Centre expertise [19]. Therefore, in patients lacking a healthy sibling donor, which is likely to be a problem in this advanced-age group, a search for an unrelated donor should 
Table 3. Analysis of Factors Affecting Survival, Relapse Rate and Nonrelapse Mortality (NRM)

\begin{tabular}{|c|c|c|c|c|c|c|}
\hline & $\frac{\text { Survival Rate }}{\text { After SCT }}$ & P Value & $\frac{\text { Relapse Rate }}{\text { After SCT }}$ & P Value & $\underline{\text { NRM }}$ & P Value \\
\hline All 30 PATIENTS & $17 / 30(57 \%)$ & / & $7 / 30(23 \%)$ & l & $6 / 30(20 \%)$ & / \\
\hline $\begin{array}{ll}\text { STATUS of AML at SCT } \\
\bullet \quad \text { Complete Remission } \\
\bullet \quad \text { Active Disease (Rel/Res) }\end{array}$ & $\begin{array}{c}15 / 18 \\
2 / 18\end{array}$ & $\underline{0,0004}$ & $\begin{array}{l}1 / 18 \\
6 / 12\end{array}$ & $\underline{0,008}$ & $\begin{array}{l}3 / 18 \\
3 / 12\end{array}$ & 0.3 \\
\hline $\begin{array}{cl}\text { DONOR } & \\
\bullet & \text { Sibling } \\
\bullet & \text { Unrelated }\end{array}$ & $\begin{array}{c}10 / 18 \\
7 / 12\end{array}$ & 0,6 & $\begin{array}{l}3 / 18 \\
4 / 12\end{array}$ & 0,3 & $\begin{array}{l}4 / 18 \\
2 / 12\end{array}$ & 0.5 \\
\hline $\begin{array}{cl}\text { STEM } & \text { CELL SOURCE } \\
\bullet & \text { Bone Marrow } \\
\bullet & \text { Pheripheral Blood }\end{array}$ & $\begin{array}{c}6 / 11 \\
11 / 10\end{array}$ & 0,7 & $\begin{array}{l}2 / 11 \\
5 / 19\end{array}$ & 0,5 & $\begin{array}{l}3 / 11 \\
3 / 19\end{array}$ & 0.3 \\
\hline $\begin{array}{cl}\text { PREPARATIVE } & \text { REGIMEN } \\
\text { - } & \text { Tyothepa-EDX } \pm \text { ATG } \\
\text { - } & \text { Fluda based-RIC } \\
\text { - } & \text { Bu-EDX } \pm \text { ATG } \\
\end{array}$ & $\begin{array}{c}9 / 14 \\
7 / 12 \\
1 / 4\end{array}$ & 0,2 & $\begin{array}{c}2 / 14 \\
4 / 12 \\
1 / 4\end{array}$ & 0,8 & $\begin{array}{c}3 / 14 \\
1 / 12 \\
2 / 4\end{array}$ & 0.15 \\
\hline $\begin{array}{r}\text { AGE } \\
\qquad \quad<65 \\
\bullet \quad \geq 65 \\
\end{array}$ & $\begin{array}{c}10 / 17 \\
7 / 13\end{array}$ & 0,7 & $\begin{array}{l}4 / 17 \\
3 / 13\end{array}$ & 0,7 & $\begin{array}{l}3 / 17 \\
3 / 13\end{array}$ & 0.3 \\
\hline $\begin{array}{r}\frac{\text { HCT-CI }}{\bullet} \\
\bullet 2 \\
\bullet \quad \geq 3\end{array}$ & $\begin{array}{c}10 / 12 \\
7 / 18\end{array}$ & $\underline{0,02}$ & $\begin{array}{l}2 / 12 \\
5 / 18\end{array}$ & 0,4 & $\begin{array}{l}0 / 12 \\
6 / 18\end{array}$ & $\underline{0.03}$ \\
\hline
\end{tabular}

Table 4. Available Studies Evaluating Allo-SCT for AML $\geq 60$ Yrs

\begin{tabular}{|c|c|c|c|c|c|}
\hline & No of Cases & Median Age (Range) & Conditioning & OS (1 Yrs) & NRM \\
\hline \hline Bertz et al. $2003[5]$ & 19 & $64(60-70)$ & RIC $19 / 19$ & $68 \%$ & $22 \%(1 \mathrm{yr})$ \\
\hline De Lima et al. $2004[17]$ & 40 & $67(65-75)$ & RIC $40 / 40$ & $43 \%$ & $30 \%$ \\
\hline Shapira et al. $2004[15]$ & 17 & $62,5(60-67)$ & RIC $13 / 13$ & $29 \%$ & $33 \%(1 \mathrm{yrs})$ \\
\hline Gupta et al. $2005[16]$ & 24 & $64(60-71)$ & RIC $24 / 24$ & $60 \%$ & $25 \%(2 \mathrm{yrs})$ \\
\hline Falda et al. $2007[18]$ & 26 & $>60$ & RIC $26 / 26$ & $58 \%$ & $11 \%$ \\
\hline Present Report, 2010 & 30 & $63(60-70)$ & RIC $26 / 30$ & $57 \%$ & $20 \%(1 \mathrm{yr})$ \\
\hline
\end{tabular}

be rapidly started especially in cases without severe comorbidities.

Our data, in line with those from other groups, suggest that older age by itself should not be the limiting factor for proceeding to allo-SCT $[5,15-18]$. In the elderly AML population the hematopoietic cell transplantation comorbidity index (HCT-CI), developed by Sorror and coworkers, should be used to estimate treatment related risk and to guide decision on allo-SCT [20].

In conclusion, considering that this is a retrospective analysis with a small number of cases, these results confirm the feasibility of allo-SCT for high risk AML patients older than 60 years. In this experience NRM rate is only $20 \%$ and OS rate (1 year 57\%) is promising taking into account the poorer outcome of elderly AML patients. Favourable outcome was observed especially in patients with a low HCT-CI (2 or less) and in those transplanted while in complete remission. We also confirm that for elderly AML patients lacking a suitable family donor MUD can provide a suitable alternative option. The evaluation of HCT-CI in elderly, before transplant procedure, could help decision making and should be considered an important part of pre transplant assessment.

\section{REFERENCES}

[1] Appelbaum FR, Gundacker H, Head DR, et al. Age and acute myeloid leukemia. Blood 2006; 107: 3481-5.

[2] Deschler B, De Witte T, Mertelsmann R, et al. Treatment decision making for older patients with high-risk myelodysplastic syndrome or acute myeloid leukemia: problems and approaches. Haematologica 2006; 91: 1513-22.

[3] De Lima M, Giralt S. Allogeneic transplantation for the elderly patient with acute myelogenous leukemia or myelodysplastic syndrome. Semin Hematol 2006; 43:107-17.

[4] Kiss TL, Sabry W, Lazarus HM, et al. Blood and marrow transplantation in elderly acute myeloid leukaemia patients: older certainly is not better. Bone Marrow Transplant 2007; 40: 405-16. 
[5] Bertz H, Potthoff K, Finke J. Allogeneic stem-cell transplantation from related and unrelated donors in older patients with myeloid leukemia. J Clin Oncol 2003; 21:1480-4.

[6] Shimoni A, Kroger N, Zabelina T, et al. Hematopoietic stem-cell transplantation from unrelated donors in elderly patients (age $>55$ years) with hematologic malignancies: older age is no longer a contraindication when using reduced intensity conditioning. Leukemia 2005; 19: 7-12.

[7] Miller AB, Hoogstraten B, Staquet M, et al. Reporting results of cancer treatment. Cancer 1981; 47: 207-14.

[8] Przepiorka D, Weisdorf D, Martin P, et al. 1994 Consensus Conference on Acute GVHD Grading. Bone Marrow Transplant 1995; 15: 825-8.

[9] Thiede C, Bornhauser M, Oelschlagel U, et al. Sequential monitoring of chimerism and detection of minimal residual disease after allogeneic blood stem cell transplantation (BSCT) using multiplex PCR amplification of short tandem repeat-markers. Leukemia 2001; 15: 293-302.

[10] Cheson BD, Bennett JM, Kopecky KJ, et al. Revised recommendations of the international Working Group for Diagnosis, Standardization of response Criteria, Treatment Outcomes, and reporting Standards for therapeutic Trials in acute myeloid leukemia. J Clin Oncol 2003; 21: 4642-9.

[11] Shapira MY, Tsirigotis P, Resnick IB, et al. Allogeneic hematopoietic stem cell transplantation in the elderly. Crit Rev Oncol Hematol 2007; 64: 49-63.

[12] Blaise D, Vey N, Faucher C, et al. Current status of reduced intensity conditioning allogeneic stem cell transplantation for acute myeloid leukemia. Haematologica 2007; 92: 533-41.

[13] Appelbaum FR. What is the impact of hematopoietic cell transplantation (HCT) for older adults with acute myeloid leukaemia (AML)? Best Pract Res Clin Haematol, 2008; 21: 665-7.
[14] Niederwieser D, Lange $T$, Cross $M$, et al. Reduced intensity conditioning (RIC) haematopoietic cell transplants in elderly patients with AML. Best Pract Res Clin Haematol 2006; 19: 82538.

[15] Shapira MY, Resnick IB, Bitan M, et al. Low transplant-related mortality with allogeneic stem cell transplantation in elderly patients. Bone Marrow Transplant 2004; 34: 155-9.

[16] Gupta V, Daly A, Lipton HJ, et al. Nonmyeloablative Stem Cell Transplantation for Myelodysplastic Syndrome or Acute Myeloid Leukemia in patients 60 years or older. Biol Blood Marrow Transplant 2005; 11: 764-72.

[17] De Lima M, Shahjahan M, Alamo J, et al. Allogeneic hematopoietic stem cell transplantation (HSCT) for patients aged 65 years or older with AML and MDS. Blood 2004; 104: A 2301.

[18] Falda M, Busca A, Baldi I, et al. Nonmyeloablative allogeneic stem vcell transplantation in elderly patients with hematological malignancies: Results from the GITMO (Gruppo Italiano Trapianto di Midollo) multicenter prospective clinical trial. Am J Hemat 2007; 82: 863-6.

[19] Scheteling J, Bornhauser M, Schmid C, et al. Matched unrelated or matched sibling donors result in comparable survival after allogeneic stem-cell transplantation in elderly patients with acute myeloid leukemia: a report from the German Transplant Study Group. J Clin Oncol 2008; 26: 5183-91.

[20] Sorror ML, Sandmaier BM, Storer BE, et al. Comorbidity and Disease status Based Risk Stratification of Outcomes among patients with acute myeloid leukaemia or myelodysplasia receiving allogeneic hematopoietic cell transplantation. J Clin Oncol 2007; 25: 4246-54

(C) Candoni et al.; Licensee Bentham Open.

This is an open access article licensed under the terms of the Creative Commons Attribution Non-Commercial License (http: //creativecommons.org/licenses/by$\mathrm{nc} / 3.0 /$ ) which permits unrestricted, non-commercial use, distribution and reproduction in any medium, provided the work is properly cited. 